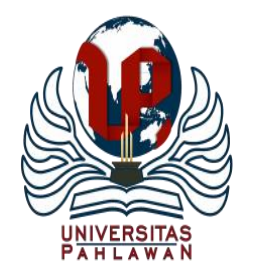

Jurnal Abdidas Volume 1 Nomor 3 Tahun 2020 Halaman 95- 99

JURNAL ABDIDAS

Community Development Service on Educational and Health Sciences

http://abdidas.org/index.php/abdidas

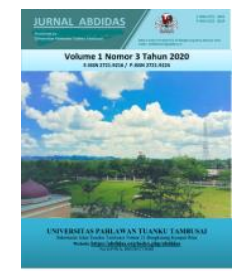

\title{
PELATIHAN PENGENALAN DATA SCIENCE UNTUK MENINGKATKAN KEMAMPUAN DALAM PENGOLAHAN DATA
}

\author{
Hairani $^{1}$, Ahmad Zuli Amrullah ${ }^{2}$ \\ Universitas Bumigora ${ }^{1,2}$ \\ E-mail : hairani@universitasbumigora.ac.id ${ }^{1}$, zuli@ universitasbumigora.ac.id $^{2}$
}

\begin{abstract}
Abstrak
Data science merupakan gabungan ilmu komputer, statistika, dan pengetahuan domain bisnis untuk ekstraksi tumpukan data yang besar menjadi pengetahuan sehingga mendapatkan pattern atau pola-pola yang dapat memudahkan pengambil keputusan. Adapun orang menggeluti bidang data science disebut data scientist. Profesi data scientist akhir-akhir ini menjadi profesi yang sangat seksi di abad 21. Sumber daya manusia yang berprofesi sebagai data scientist di Indonesia sangat sedikit bila dibandingkan ketersedian lapangan kerja dibidang data science. Dengan kata lain, ketersediaan lapangan kerja data science berbanding terbalik dengan ketersediaan SDM yang berprofesi sebagai data scientist, dimana jumlah SDM data scientist sangat sedikit dibandingkan dengan jumlah lapangan kerja yang berlimpah. Salah satu solusi yang ditawarkan adalah mengadakan pelatihan dan workshop untuk pengenalan data science untuk meningkatkan SDM bidang data science khususnya di Universitas Bumigora. Metode pelaksanaan yang digunakan adalah penyampaian materi tentang data science dan simulasi penggunaan metode data science dalam kasus real menggunakan Google Colab. Berdasarkan hasil pelatihan dan workshop yang telah dilaksanakan, dapat meningkatkan pemahaman dan kemampuan para peserta untuk menggunakan metode-metode yang ada pada data science untuk mengolah data menjadi sebuah pengetahuan.
\end{abstract}

Kata kunci: data science, pelatihan, workshop, data scientist

\begin{abstract}
Data science is a combination of computer science, statistics, and business domain knowledge for extracting large heaps of data into knowledge so as to obtain patterns that can facilitate decision makers. The people in the field of data science are called data scientists. The data scientist profession has recently become a very sexy profession in the 21 st century. Human resources who work as data scientists in Indonesia are very few when compared to the availability of employment in the field of data science. In other words, the availability of data science employment is inversely proportional to the availability of human resources who work as data scientists, where the number of HR data scientists is very small compared to the abundant number of jobs. One of the solutions offered is to hold training and workshops for the introduction of data science to improve human resources in the field of data science, especially at Bumigora University. The implementation method used is the delivery of material about data science and simulation of the use of data science methods in real cases using Google Colab. Based on the results of training and workshops that have been carried out, it can increase the understanding and ability of the participants to use existing methods in data science to process data into knowledge.
\end{abstract}

Keywords: data science, training, workshop, data scientist

Copyright (c) 2020 Hairani, Ahmad Zuli Amrullah

$\triangle$ Corresponding author:

Address : Perumahan Panorama Alam Orange

ISSN 2721-9224 (Media Cetak)

Email : Hairani@universitasbumigora.ac.id

ISSN 2721- 9216 (Media Online)

Phone : 087839793970

DOI :_https://doi.org/10.31004/abdidas.v1i3.31

Jurnal Abdidas Vol 1 No 3 Tahun 2020 p-ISSN 2721-9224 e-ISSN 2721-9216 


\section{PENDAHULUAN}

Di era Revolusi Industri 4.0 semua organisasi atau perusahaan menerapkan teknologi informasi dalam menunjang bisnisnya, sehingga lebih efisien dan efektif. Akibat dari penggunaan teknologi informasi tersebut menghasilkan data dalam jumlah besar dan belum dimanfaatkan sepenuhnya. Tumpukan data tersebut dapat diolah menjadi sebuah pengetahuan sehingga dapat memudahkan pengambil keputusan untuk membuat kebijakan kedepannya. Salah satu solusinya adalah menggunakan teknik data science atau ilmu data.

Data science merupakan gabungan ilmu komputer, statistika, dan pengetahuan domain bisnis untuk ekstraksi tumpukan data yang besar menjadi pengetahuan sehingga mendapatkan pattern atau pola-pola yang dapat memudahkan pengambil keputusan (Igual \& Segui, 2017). Adapun orang menggeluti bidang data science disebut data scientist (Rahman, 2015). Profesi data scientist akhir-akhir ini menjadi profesi yang sangat seksi di abad 21. Sumber daya manusia yang berprofesi sebagai data scientist di Indonesia sangat sedikit bila dibandingkan ketersediaan lapangan kerja di bidang data science (Yusuf, 2018).

Dengan kata lain, ketersediaan lapangan kerja data science berbanding terbalik dengan ketersediaan SDM yang berprofesi sebagai data scientist, dimana jumlah SDM data scientist sangat sedikit dibandingkan dengan jumlah lapangan kerja yang berlimpah. Salah satu kegunaan data science adalah dapat melakukan pengolahan data menjadi pengetahuan dengan menggunakan beberapa teknik seperti mampu memprediksikan data di masa depan menggunakan metode Regresi Linier (Sulistyono \& Sulistiyowati, 2018) dan mampu mengklasifikasikan data menggunakan metode Naïve Bayes (Hairani et al., 2018), C.45 (Gunawan et al., 2020), Support Vector Machine (SVM)(Hairani et al., 2020), k-Nairest Neigboart (k-NN)(Jadhav \& Channe, 2016). Tidak hanya itu, kemampuan dalam bidang data science dapat mengelompokkan data berdasarkan kemiripannya menggunakan metode K-Means (Yuda Irawan, 2019) (Nugraha \& Hairani, 2018).

Untuk menjadi seorang ahli di dalam bidang data science dibutuhkan kemampuan seperti statistika, programming, dan pengetahuan domain permasalahan. Tidak hanya itu, seorang data scientist harus mampu menggunakan metodologi pengolahan data menjadi pengetahuan. Adapun metodologi pengolahan data di bidang data science ditunjukkan pada Gambar 1.

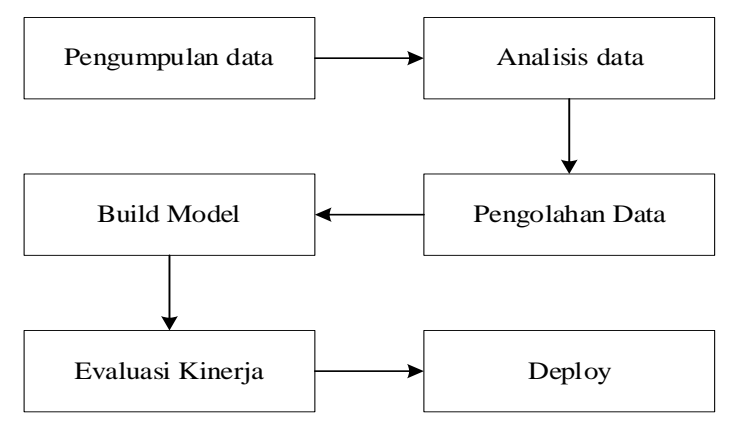

Gambar 1: Metodologi Pengolahan Data Science

Salah satu solusi yang ditawarkan untuk mengatasi permasalahan kekurangan sumber daya manusia di bidang data science adalah mengadakan pelatihan dan workshop dalam rangka untuk memperkenalkan bidang data science 
sehingga dapat meningkatkan kemampuan dalam pengolahan data menjadi sebuah pengetahuan dan juga dapat digunakan sesuai kepentingan. Dengan adanya pelatihan dan workshop tersebut diharapkan dapat meningkatkan Sumber Daya Manusia (SDM) untuk menggeluti bidang data science. Para peserta yang ditargetkan dalam pelatihan ini adalah mahasiswa Universitas Bumigora dengan jurusan Ilmu Komputer, Statistika, dan Ekonomi.

\section{METODE}

Pelaksanaan pelatihan dan workshop pengenalan data science tersebut dilaksanakan pada hari Jumat, 20 Desember 2019 bertempat di Aula Universitas Bumigora dengan mengambil tema pengenalan data science untuk kemajuan pariwisata NTB di era Revolusi Industri 4.0. Adapun metode pelaksanaannya dilakukan dengan dua sesi yaitu sesi pertama penyampaian teori data science yang disampaikan oleh Ahmad Zuli Amrullah, M.Eng, dan Hairani, M.Eng. Kemudian sesi kedua melakukan simulasi untuk implementasi salah satu teknik data science yaitu melakukan prediksi dengan kasus real menggunakan metode Regresi Linier berbasis Google Colab. Adapun susunan acaranya ditunjukkan pada Tabel 1.

Tabel 1. Susunan Acara

\begin{tabular}{cl}
\hline \multicolumn{1}{c}{ Jam } & \multicolumn{1}{c}{ Kegiatan } \\
$08.00-08.30$ & Registrasi peserta seminar \\
$08.30-09.00$ & Sambutan dan pengenalan Data Science Weekend \\
$09.00-10.00$ & Pengenalan Data Science \\
$10.00-10.15$ & Sesi tanya jawab 1 \\
$10.15-11.15$ & Potensi penelitian bidang Data Science \\
$11.15-11.30$ & Sesi tanya jawab 2 \\
$11.30-13.30$ & Ishoma \\
$13.30-14.00$ & Registrasi peserta workshop \\
$14.00-16.00$ & Workshop dengan Google Colab \\
$16.00-16.30$ & Sesi tanya jawab 3 \\
$16.30-17.00$ & Penutupan acara \\
\hline
\end{tabular}

\section{HASIL DAN PEMBAHASAN}

Kegiatan pengabdian dilaksanakan pada tanggal 20 Desember 2019 di Aula Universitas Bumigora. Peserta yang menghadiri kegiatan tersebut sebagian besar mahasiswa Ilmu Komputer, Teknologi Informasi dan umum.
Pelaksanaan kegiatan pengabdian ini diawali dengan penyampaian teori tentang data science dan dilanjutkan simulasi menggunakan Google Colab untuk implementasi metode data science untuk kasus nyata. Adapun dokumentasi acara 
pengabdian tersebut, ditunjukkan pada Gambar 2,

Gambar 3, Gambar 4, dan Gambar 5.

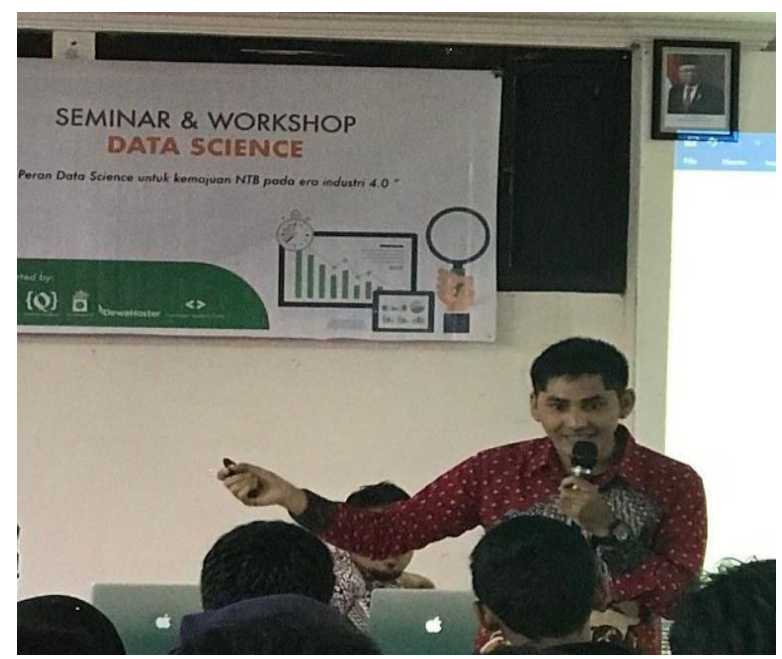

Gambar 2: Pemateri Pengenalan Data Science

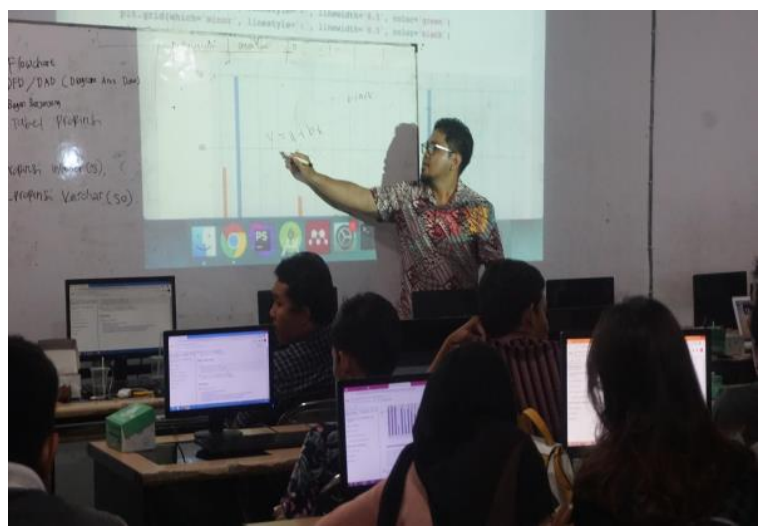

Gambar 3: Pemateri Tutorial Data Science

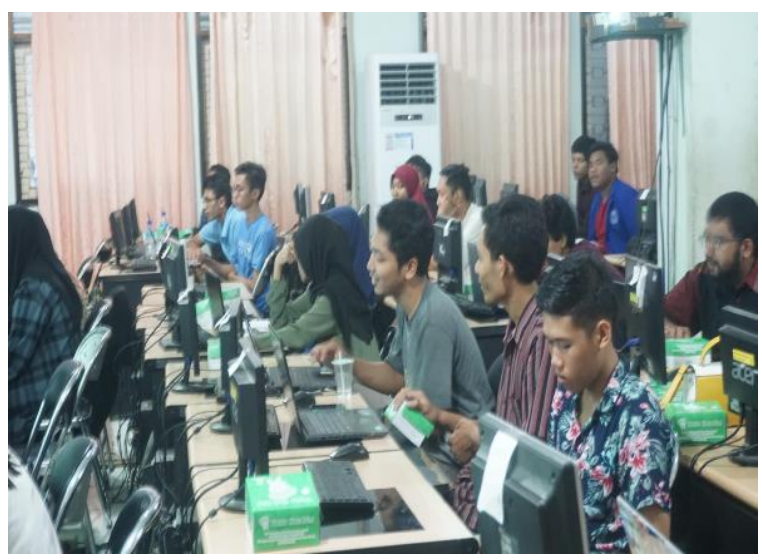

Gambar 4: Peserta Tutorial Data Science

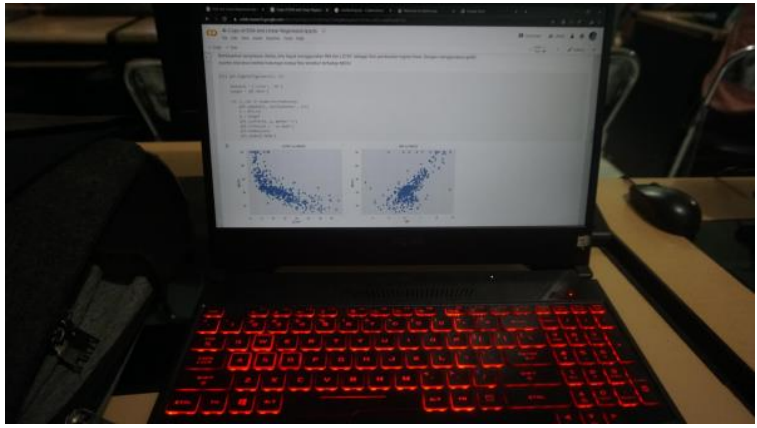

Gambar 5: Hasil Tutorial Data Science Oleh Peserta

Berdasarkan hasil pelatihan dan workshop yang telah dilakukan dapat memberikan pemahaman dan kemampuan terhadap peserta yang hadir tentang bidang data science. Tidak hanya itu, para peserta mampu mengimplementasikan metode-metode yang ada pada data science untuk mengolah data menjadi pengetahuan menggunakan Google Colab seperti prediksi menggunakan metode Regresi Linier, klasifikasi menggunakan metode Naive Bayes, SVM, k-NN, C4.5, dan lain-lain.

\section{SIMPULAN}

Berdasakan kesimpulan yang dapat ditarik dari hasil pelatihan dan workshop data science adalah para peserta yang hadir dapat memberikan pemahaman dan kemampuan terhadap peserta yang hadir tentang bidang data science. Tidak hanya itu, para peserta mampu mengimplementasikan metode-metode yang ada pada data science untuk mengolah data menjadi pengetahuan menggunakan Google Colab seperti prediksi menggunakan metode Regresi Linier, klasifikasi menggunakan metode Naive Bayes, SVM, k-NN, C4.5, dan lain-lain. 


\section{UCAPAN TERIMA KASIH}

Penulis ucapkan rasa terima kasih kepada Rektor Universitas Bumigora, Kaprodi Jurusan Teknologi Informasi yang telah memberikan izin dalam pelaksanaan pelatihan dan workshop data science.

\section{DAFTAR PUSTAKA}

Gunawan, Hanes, \& Catherine. (2020). Information Systems Students' Study Performance Prediction Using Data Mining Approach. $\quad 1-8$. https://doi.org/10.1109/icic47613.2019.89857 18

Hairani, H., Nugraha, G., Nurkholis Abdillah, M., \& Innuddin, M. (2018). Komparasi Akurasi Metode Correlated Naive Bayes Classifier dan Naive Bayes Classifier untuk Diagnosis Penyakit Diabetes. InfoTekJar (Jurnal Nasional Informatika Dan Teknologi Jaringan), $\quad 3(1), \quad 6-11$. https://doi.org/10.30743/infotekjar.v3i1.558

Hairani, H., Saputro, K. E., \& Fadli, S. (2020). Kmeans-SMOTE untuk menangani ketidakseimbangan kelas dalam klasifikasi penyakit diabetes dengan C4.5, SVM, dan naive Bayes. Jurnal Teknologi Dan Sistem Komputer, 8(2), 89-93. https://doi.org/https://doi.org/10.14710/jtsisko m.8.2.2020.89-93

Igual, L., \& Segui, S. (2017). Introduction to Data Science A Python Approach to Concepts, Techniques and Applications. Springer.

Jadhav, S. D., \& Channe, H. P. (2016). Comparative Study of $K-N N$, Naive Bayes and Decision Tree Classification Techniques. 5(1), 2014-2017.

Nugraha, G. S., \& Hairani, H. (2018). Aplikasi Pemetaan Kualitas Pendidikan di Indonesia Menggunakan Metode K-Means. MATRIK: Jurnal Manajemen, Teknik Informatika Dan Rekayasa Komputer, 17(2), 13-23.
Rahman, A. F. (2015). Profesi Data Scientist, Seperti Apa Sih? https://inet.detik.com/business/d3079489/profesi-data-scientist-seperti-apa-sih

Sulistyono, S., \& Sulistiyowati, W. (2018). Peramalan Produksi dengan Metode Regresi Linier Berganda. PROZIMA (Productivity, Optimization and Manufacturing System Engineering), $\quad$ 1(2), 82. https://doi.org/10.21070/prozima.v1i2.1350

Yuda Irawan. (2019). Implementation Of Data Mining For Determining Majors Using KMeans Algorithm In Students Of SMA Negeri 1 Pangkalan Kerinci. Journal of Applied Engineering and Technological Science (JAETS), $\quad 1(1), \quad 17-29$. https://doi.org/10.37385/jaets.v1i1.18

Yusuf, O. (2018). Talenta Data Scientist di Indonesia, Permintaan Tinggi Pasokan Kurang. Https://Tekno.Kompas.Com/. https://tekno.kompas.com/read/2018/03/23/09 210087/talenta-data-scientist-di-indonesiapermintaan-tinggi-pasokan-kurang 